\title{
Anthropometric and Physical Fitness Characterization of Male Elite Karate Athletes
}

\author{
Caracterización Antropométrica y Estado Físico de Atletas de Elite de Karate Masculino
}

\author{
María B. Sánchez-Puccini*; Rodrigo E. Argothy-Bucheli**; José F. Meneses-Echávez***; \\ Carlos Alejandro López-Albán ${ }^{* * * * *}$ \& Robinson Ramírez-Vélez ${ }^{* * *}$
}

SÁNCHEZ-PUCCINI, M. B.; ARGOTHY-BUCHELI, R. E.; MENESES-ECHÁVEZ, J. F.; LÓPEZ-ALBÁN, C.A. \& RAMÍREZVÉLEZ, R. Anthropometric and physical fitness characterization of male elite karate athletes. Int. J. Morphol., 32(3):1026-1031, 2014.

SUMMARY: This study aimed to assess anthropometric and physical fitness characteristics of male elite karate athletes. Our study was carried out on a sample of 19 male Karate Athletes from Colombia (mean age 31.6 \pm 8.8 years). Different anthropometric measurements were taken (weight, height, diameters, circumferences, body composition) from which several anthropometric indices were calculated (body mass index, ponderal index, body index adiposity), and the somatotype was then determined. The performance tests carried out were: Astrand-Ryming protocol, vertical jump, anaerobic power and Wingate anaerobic test. The results (mean \pm SD) showed a body mass (65.4 \pm 12.0 $\mathrm{kg}$ ), height $(167.4 \pm 9.3 \mathrm{~cm})$, percent body fat $(13.6 \pm 3.0 \%)$, ponderal index $(41.0 \pm 1.8)$ and body adiposity index (25.1 \pm 3.6$)$. The somatotype component values according to the Heath-Carter method were (4.0-4.2-2.1) for the endomorphic, mesomorphic, and ectomorphic components respectively. The aerobic capacity average was $\left(44.8 \pm 7.1 \mathrm{ml} \bullet \mathrm{kg}^{-1} \bullet \mathrm{min}^{-1}\right)$, vertical jump $(32.0 \pm 8.7 \mathrm{~cm})$ anaerobic power $\left(90.1 \pm 22.7 \mathrm{~kg} \bullet \mathrm{s}^{-1}\right)$ and anaerobic capacity $(5748.7 \pm 1477.5 \mathrm{~W})$. These results may provide a profile of elite karate that can be used as training targets for developing athletes. Our findings provide novel insight for both tactical and functional training.

KEY WORDS: Karate; Body Composition; Somatotype; Fitness; Anthropometry.

\section{INTRODUCTION}

Anthropometric characteristics are part of the biological variables related with sport performance. It is completely established that anthropometry is an important selection factor (Moreno et al., 2011), as well as mean to detect future sports talents (García et al., 2007; Popovic et al., 2013). The reason for this is that somatotype is associated with motor efficiency (Sterkowics-Przybycien, 2010).

Several studies have been made to characterize the body composition of athletes practicing karate (Giampietro et al., 2003; Moreno et al.; Sterkowics-Przybycien) to provide an outline of the morphological and functional biotype. These studies have been performed in athletes form different countries, which can be related with different physical characteristics. In 2003, Giampietro et al., examined the anthropometric features and body composition of 35 subjects practicing karate in Italy; this sample included elite athletes as well as amateur athletes. Pieter \& Barcades (2009) assessed and compared the somatotypes of elite combative sports athletes, the sample of their study included Philippine males and females from three different disciplines. Twelve of the subjects were members of the Philippine national senior teams in karate. In 2010, Sterkowics-Przybycien determined the body composition and somatotype of thirty male karateists grouped by different level of competition.

A few researches have been performed to evaluate the Latin-American karate athletes; however the subjects for these studies have been athletes from lower categories. During the XVI Pan-American Junior Championship which took place in Montevideo, Uruguay in 2005, Huertas et al. (2006) performed a descriptive analysis of anthropometric variables from a sample of the athletes who participated in the championship. In 2011, Moreno et al., published a characterization of Karate athletes from two universities in Colombia. In these two studies researches assessed

* PhD Student Healthcare Science, Faculty of Engineering and Science School of Healthcare and Science, Manchester Metropolitan University, UK.

** Estudiante de Maestría en Ingeniería Biomédica, Facultad de Medicina, Universidad Nacional de Colombia, Bogotá, Colombia.

**** Grupo GICADES, Facultad de Cultura Física, Deporte y Recreación, Universidad Santo Tomás, Bogota, Colombia.

***** Centro Para La Investigación en Salud y Rendimiento Humano ZOE, Cali, Colombia. 
anthropometric variables such as height, weight, and percentage of fat mass, among others. Nevertheless, there are no studies that have focused specifically in Colombian elite athletes.

The karate Colombian Team was evaluated as part of the preparation for the London 2012 Olympic Games. Assessment of fitness profiles in these subjects can contribute to talent selection and could be of decisive importance for optimizing strength, muscle power, and endurance training programs to improve elite performance. In light of this consideration, the objective of the present study was to analyze anthropometric and physical fitness characteristics of male elite karate athletes. It is expected that this information would assist sport medicine and other health professionals to a better understanding and monitoring of the anthropometric, morphological and physiological variations among karate athletes.

\section{MATERIAL AND METHOD}

Subjects and procedure . A cross-sectional study in 19 male Karate Athletes from the Indervalle (Instituto Nacional de Deportes, Educación Física y Recreación del Valle del Cauca-Colombia) was performed. All the participants took part in elite competitions between 2008 and 2012. Subjects were 27-35 years old with a mean age \pm standard deviation (SD) of 31.6 \pm 8.8 , and had at least 3 years of active participation in elite categories. All volunteers were examined in a medical research center, signed declarations of informed consent and of agreement to participate in the study. Ethical approval has obtained from the ethics committee of Indervalle. Exclusion criteria were previous diagnosis of inflammatory or metabolic diseases (diabetes, thyroid gland disease, any other endocrine disorders; autoimmune diseases; any chronic inflammation; and neoplastic disease). All variables were measured by a Level 2 anthropometrist certified by the International Society for the Advancement of Kinanthropometry (ISAK), in accordance with the ISAK guidelines (Marfell-Jones et al., 2006). Measurements were taken in the morning between 09:00 and 11:00 am for all the subjects, after an overnight fast.

Anthropometric, body composition and somatotype characteristics. Body weight was measured to the nearest $0.1 \mathrm{~kg}$ using an electronic scale (Seca 700 scale, Seca gmbh, Hamburg). Height was measured to the nearest $0.1 \mathrm{~cm}$ using a stadiometer (Seca 220 (CM) Telescopic Height Rod for Column Scales, Seca gmbh, Hamburg). Circumferences measurements were taken around the flexed arm, relaxed arm, forearm, thigh, calf, chest, waist, and hip with a constant-tension steel tape (Sanny, Brazil). Diameters of the elbow, knee, and wrist joints, and the biacromial, and biiliac breadths were taken (Body Trends, Carpinteria, CA). Skinfold-thickness sites included biceps, triceps, subscapular, chest, abdominal, suprailiac, anterior thigh, and medial calf. These measurements were taken on the right side of the body with the Lange skinfold caliper (Holtain Ltd., Crymych, Dyfed) and were used in the assessment of body fat (\%), absolute body fat (kg), muscle mass (\%) and absolute muscle mass $(\mathrm{kg})$ from the nomogram proposed by Jackson and Pollock (Nevill et al., 2008). Somatotype was determined by the Heath-Carter anthropometric somatotype method (Carther \& Heath, 1990). Using these measurements the ponderal index (height·weight-1/3) was calculated. Body adiposity index (BAI) was calculated using the equation [(hip circumference-height-1.5)-18], which refers to Bergman et al. (2011).

Aerobic, leg muscle power, and anaerobic power characteristics . Aerobic capacity assessment was obtained by the use of a Monark $818 \mathrm{E}$ cycle ergometer (Monark AB, Varberg, Sweden) interfaced with the computer. A modified Astrand-Ryming protocol contained in the software predicted the subjects' VO(2)max (Clirk and Thomas, 1981). $\mathrm{VO}(2) \mathrm{max}$ data is represented relative to body mass $\left(\mathrm{ml} \bullet \mathrm{kg}^{1} \bullet \mathrm{min}^{-1}\right)$ and Mets. During the test heart rate (HR) was monitored electronically using a Polar A-5 pulse meter (Polar Electro Oy, Kernpele, Finland). Anaerobic power was determined by Sargent Vertical Jump and Standing Broad Jump. Vertical jump height was measured and, by using body weight, was converted by the Lewis nomogram to anaerobic power. Standing broad jump was also used to evaluate leg muscle power (Vodak, 1983). The Wingate Anaerobic Test (WAnT) was performed according to procedures described earlier (Bar-Or, 1987). The Wingate test was administered for 30 seconds and resistance was set at $7.5 \%$ of body mass. Participants were seated on the Monark ergometer (Monark AB, Varberg, Sweden) and adjustments to the ergometer were made to ensure an optimal riding position. Verbal encouragement was provided by the investigators. Peak power (PP) and anaerobic capacity (AC) were calculated and recorded in watts (W) and watts per kilogram body weight $\left(\mathrm{W} \bullet \mathrm{kg}^{-1}\right)$. The fatigue index $(\mathrm{FI})$ express in percentage was calculated from the data obtained with the Wingate test. HR was recorded in beats per minute (bpm).

Statistical analysis. All data were subjected to statistical analyses using IBM SPSS Statistics 20.0 software (SPSS/ IBM, Chicago, IL, USA). Anthropometry, body composition, somatotype, aerobic capacity, leg muscle power, and anaerobic power were expressed as mean \pm standard deviation (SD) and Confidence Interval (95\% CI). 


\section{RESULTS}

Anthropometric characteristics of the athletes evaluated in this study are presented in Table I. Participants were $31.6 \pm 8.8$ years old, had a height average of $167.4 \pm 9.3$ $\mathrm{cm}$, and a mean body mass of $65.4 \pm 12.0 \mathrm{~kg}$. Mean values for the circumferences, diameters, and skinfolds taken are fully reported in Table I.
The information obtained from the anthropometric measurements was used to calculated body composition and somatotype characteristics (Table II). The somatotype component values according to the Heath-Carter method were $4.0 \pm 1.6,4.2 \pm 1.2$, and $2.1 \pm 1.1$ for the endomorphic, mesomorphic, and ectomorphic components respectively.

Table I. Anthropometric characteristics of Colombian national team male karate athletes.

\begin{tabular}{llcc}
\hline Characteristics & & Mean \pm SD & CI 95\% \\
\hline Variables & Age (year) & $31.6 \pm 8.8$ & $(27.4-35.9)$ \\
& Height $(\mathrm{cm})$ & $167.4 \pm 9.3$ & $(162.9-171.9)$ \\
& Body mass $(\mathrm{kg})$ & $65.4 \pm 12.0$ & $(59.5-71.2)$ \\
Circumferences & Chest & $89.0 \pm 7.5$ & $(85.4-92.7)$ \\
$(\mathrm{cm})$ & Waist & $73.7 \pm 7.7$ & $(70.0-77.4)$ \\
& Hip & $92.4 \pm 8.3$ & $(88.3-96.4)$ \\
& Relaxed arm & $26.9 \pm 3.5$ & $(25.2-28.6)$ \\
& Flexed arm & $29.3 \pm 3.8$ & $(27.4-31.1)$ \\
& Forearm & $25.0 \pm 3.4$ & $(23.3-26.6)$ \\
& Thigh & $57.5 \pm 4.4$ & $(55.3-59.6)$ \\
& Calf & $35.7 \pm 2.7$ & $(34.4-37.0)$ \\
& Biacromial & $39.2 \pm 2.6$ & $(37.9-40.4)$ \\
& Biiliac & $28.4 \pm 1.9$ & $(27.5-29.3)$ \\
& Elbow & $6.1 \pm 0.5$ & $(5.9-6.4)$ \\
& Knee & $9.0 \pm 0.7$ & $(8.7-9.4)$ \\
& Wrist & $4.8 \pm 0.4$ & $(4.6-5.0)$ \\
& Triceps & $11.2 \pm 5.9$ & $(8.4-14.1)$ \\
& Biceps & $5.6 \pm 3.5$ & $(3.8-7.3)$ \\
& Subscapular & $13.2 \pm 5.9$ & $(10.3-16.0)$ \\
& Supraspinale & $10.8 \pm 7.2$ & $(7.3-14.2)$ \\
& Iliac crest & $16.2 \pm 8.2$ & $(12.2-20.1)$ \\
& Abdominal & $18.1 \pm 9.6$ & $(13.4-22.8)$ \\
& Front thigh & $15.7 \pm 8.3$ & $(11.7-19.7)$ \\
& Medial calf & $9.6 \pm 5.4$ & $(7.0-12.3)$ \\
\hline
\end{tabular}

Table II. Body composition and Somatotype characteristics of Colombian national team male karate athletes.

\begin{tabular}{llcc}
\hline Characteristics & Mean \pm SD & CI 95\% \\
\hline Body & Percent body fat & $14.7 \pm 4.3$ & $(12.6-16.7)$ \\
composition & Absolute body fat $(\mathrm{kg})$ & $9.7 \pm 4.2$ & $(7.7-11.8)$ \\
& Sum 6 skinfolds $(\mathrm{mm})^{\mathrm{a}}$ & $76.9 \pm 38.2$ & $(58.4-95.3)$ \\
& Sum 8 skinfolds $(\mathrm{mm})^{\mathrm{b}}$ & $110.1 \pm 54.1$ & $(84.0-136.2)$ \\
& Muscle mass $(\%)$ & $45.3 \pm 2.4$ & $(44.1-46.5)$ \\
Indexes & Absolute muscle mass $(\mathrm{kg})$ & $29.5 \pm 4.8$ & $(27.1-31.8)$ \\
& Ponderal index & $41.7 \pm 1.9$ & $(40.8-42.7)$ \\
& BAI & $24.8 \pm 5.0$ & $(22.4-27.2)$ \\
& Endomorphy & $4.0 \pm 1.6$ & $(3.2-4.8)$ \\
& Mesomorphy & $4.2 \pm 1.2$ & $(3.6-4.8)$ \\
& Ectomorphy & $2.1 \pm 1.1$ & $(1.6-2.6)$ \\
& X-axis & $1.9 \pm 2.5$ & $(0.7-3.1)$ \\
& Y-axis & $2.2 \pm 3.4$ & $(0.5-3.8)$ \\
\hline
\end{tabular}

aSum of triceps, subscapular, supraspinale, abdominal, front thigh and medial calf.

bSum of triceps, subscapular, biceps, iliac crest, supraspinale, abdominal, front thigh and medial calf. 
This information served to characterize the entire group of Karate athletes as mesomorphic -endomorphic, as shown in Figure 1.

From the aerobic test the results show that the complete group has a $\mathrm{VO}(2) \max$ of $44.8 \pm 7.1 \mathrm{ml} \cdot \mathrm{kg}^{-1} \bullet \mathrm{min}^{-1}$, that can be generally qualified as good (Table III). The results from the vertical jump show the mean jump height as $32.0 \pm 8.7 \mathrm{~cm}$, which represents an anaerobic power of $90.1 \pm 22.7 \mathrm{~kg} \bullet \mathrm{s}^{-1}$. Wingate test showed a peak power of $591.9 \pm 91.0 \mathrm{~W}$, an anaerobic capacity of $5748.7 \pm 1477.5 \mathrm{~W}$, and a fatigue index of $34.1 \pm 14.1 \%$ (Table III).

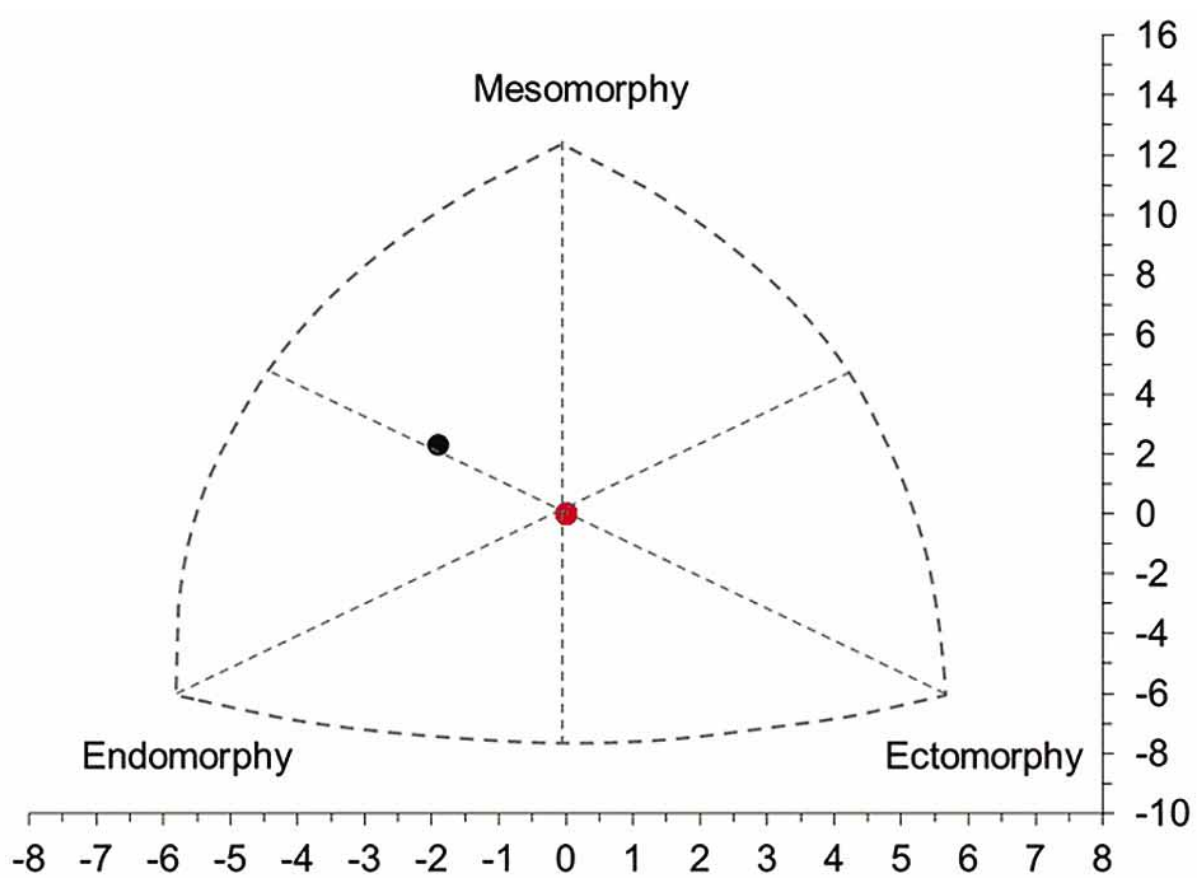

Fig. 1. Somatotype distribution according to Heath-Carter somatotype method.

Table III. Aerobic, leg muscle power, and anaerobic power measurements for performance of Colombian national team male karate athletes.

\begin{tabular}{|c|c|c|c|}
\hline \multicolumn{2}{|c|}{ Characteristics } & Mean \pm SD & CI 95\% \\
\hline \multirow[t]{4}{*}{ Aerobic } & $\mathrm{VO}(2) \max \left(\mathrm{ml} \bullet \mathrm{kg}^{-1} \bullet \mathrm{min}^{-1}\right)$ & $44.8 \pm 7.1$ & $(41.4-48.3)$ \\
\hline & Mets & $12.8 \pm 2.0$ & $(11.8-13.7)$ \\
\hline & Watt max (w) & $223.6 \pm 48.2$ & $(200.4-246.9)$ \\
\hline & HR max (bpm) & $181.7 \pm 7.7$ & $(178.0-185.5)$ \\
\hline \multirow{3}{*}{$\begin{array}{l}\text { Vertical jump } \\
(\mathrm{cm})\end{array}$} & $\operatorname{Jump}(\mathrm{cm})$ & $32.0 \pm 8.7$ & $(27.8-36)$ \\
\hline & Standing broad jump (cm) & $221.5 \pm 14.8$ & $(214.3-228.6)$ \\
\hline & Anaerobic power $(\mathrm{kg} \bullet \mathrm{s}-1)$ & $90.1 \pm 22.7$ & $(79.1-101.1)$ \\
\hline \multirow[t]{7}{*}{ Wingate test } & $\mathrm{PP}(\mathrm{W})$ & $591.9 \pm 91.0$ & $(548.0-635.8)$ \\
\hline & $\mathrm{PP}(\mathrm{W} \bullet \mathrm{kg}-1)$ & $262.1 \pm 42.8$ & $(241.5-282.8)$ \\
\hline & $\mathrm{AC}(\mathrm{W})$ & $5748.7 \pm 1477.5$ & $(5036.5-6460.8)$ \\
\hline & $\mathrm{AC}\left(\mathrm{kg} \cdot \mathrm{s}^{-1}\right)$ & $17246.1 \pm 4432.5$ & (15109.7-19382.5) \\
\hline & $\mathrm{AC}(\mathrm{K} / \mathrm{jul})$ & $1724.6 \pm 443.2$ & $(1510.9-1938.2)$ \\
\hline & $\mathrm{AC}\left(\mathrm{W} \cdot \mathrm{kg}^{-1}\right)$ & $4.8 \pm 0.9$ & $(4.3-5.3)$ \\
\hline & $\mathrm{Fl}(\%)$ & $34.1 \pm 14.1$ & $27.3-40.8$ \\
\hline
\end{tabular}

$\mathrm{PP}=$ peak power; $\mathrm{AC}=$ anaerobic capacity; $\mathrm{Fl}=$ fatigue index $\mathrm{HR}=$ heart rate; $\mathrm{bpm}=$ beats per minute. 


\section{DISCUSSION}

As far as we know, no previous studies have been developed to characterized Colombian Karate elite athletes. Only Moreno et al., assessed a group of Karate athletes from Colombia; although, the subjects from this study were part of a lower division, and the characteristics evaluated were more specific to body composition. Taking in consideration the characteristics of the group evaluated in the present study, findings will be compared with the results presented in other studies for the high competition group (Giampietro et al.; Huertas et al.; Sterkowics-Przybycien, 2010).

Anthropometric characteristics. One of the more striking differences between the athletes from the present study and the subjects from previous research is that the mean age for the elite Karate athletes in Colombia is 31.6 years old; this represents 5 years more than the athletes evaluated in Sterkowics-Przybycien, almost 8 years older than the subjects from Giampietro et al. and Pieter \& Barcades, and around 12 years more than the study from Huertas et al. (Table IV). In terms of height $(167.4 \pm 9.3 \mathrm{~cm})$, there are similarities with the subjects from Pieter \& Barcades $(169.6 \pm 4.8 \mathrm{~cm})$, and the group from Central-America in Huertas et al. $(173.0 \pm 4.5 \mathrm{~cm})$. However, height is lower compared with the subjects from Giampietro et al. $(180.0 \pm 7.0 \mathrm{~cm})$, Sterkowics-Przybycien $(179.0 \pm 4.7 \mathrm{~cm})$, and the South-America and North-America group in Huertas et al. (177.5 \pm 8.6 and $175.2 \pm 7.5 \mathrm{~cm}$, respectively). In a similar way, weight was minor for Colombian athletes $(65.4 \pm 12.0$ $\mathrm{kg}$ ) in comparison with Italian (Giampietro et al., 2003), North-American (Huertas et al.) and Polish (SterkowicsPrzybycien) which weight Mean \pm SD values were $72.4 \pm 8.7$, $71.9 \pm 12.2$, and $91.1 \pm 8.2 \mathrm{~kg}$, respectively (Table IV).

Only Giampietro et al., reported the measurements for circumferences and diameters. Data reported for arm $(28.3 \pm 1.4$ $\mathrm{cm})$ and calf circumferences $(36.4 \pm 2.5 \mathrm{~cm})$, and elbow
$(6.8 \pm 0.5 \mathrm{~cm})$ and knee $(9.7 \pm 0.5 \mathrm{~cm})$ diameters, are similar to the mean measures from the present group (presented in the same order: $29.3 \pm 3.8,35.7 \pm 2.7,6.1 \pm 0.5$, and $9.0 \pm 0.7 \mathrm{~cm})$.

Body composition. Mean percentage of body fat calculated in this study was $14.7 \pm 4.3 \%$; this value is similar to the findings in Huertas et al., for the Central-America (14.2 \pm 5.3 ) and North-America (12.9 $\pm 5.1 \%)$ participants. Fat percentage values are slightly higher in Polish athletes $(16.8 \pm 2.5 \%)$. On the other hand Italian (Giampietro et al.) and SouthAmerican karate athletes have lower fat percentage values: $8.1 \pm 2.4$ and $11.0 \pm 3.2 \%$, respectively (Table IV).

Somatotype components of the male Colombian national team karate athletes have a relation different from the information in other studies. In this study the endomorphic and the mesomorophic components had similar values (4.0 \pm 1.6 and $4.2 \pm 1.2)$ while the ectomorphic had lower values $(2.1 \pm 1.1)$. In contrast with Polish athletes (Sterkowics-Przybycien), that had larger mesomorphic values $(5.8 \pm 1.8)$ than endomorphic $(3.7 \pm 1.1)$ and ectomorphic (1.3 \pm 0.8$)$. This is a similar relation to CentralAmerican athletes (Hertas et al.) (3.5-4.3-2.7) which have regional characteristics similar to Colombia (Table IV).

\section{CONCLUSION}

The present study is the first description of anthropometric and physical fitness characteristics of male elite karate athletes. It is important to know that these types of studies can be used not only to know the characteristics of a specific group of athletes, but also to see if there is any correlation between body composition and the final position in international competitions. This correlation would serve to improve training characteristics, and to lead young athletes in the discipline where their body composition would be an advantage.

Table IV. Body Composition and Somatotype characteristics of cited studies.

\begin{tabular}{|c|c|c|c|c|c|c|c|}
\hline \multirow[t]{2}{*}{ Characteristics } & \multirow{2}{*}{$\begin{array}{c}\begin{array}{c}\text { Actual study } \\
\text { (2013) }\end{array} \\
19\end{array}$} & \multirow{2}{*}{$\begin{array}{c}\text { Giampietro } \\
\text { et al. (2003) } \\
14\end{array}$} & \multicolumn{3}{|c|}{ Huertas et al. (2005) } & \multirow{2}{*}{$\begin{array}{c}\begin{array}{c}\text { Pieter \& } \\
\text { Barcades } \\
(\mathbf{2 0 0 9 )}\end{array} \\
12 \\
\end{array}$} & \multirow{2}{*}{$\begin{array}{c}\begin{array}{c}\text { Sterkowics-Przybycien } \\
(\mathbf{2 0 1 0})\end{array} \\
14\end{array}$} \\
\hline & & & 10 & 12 & 8 & & \\
\hline Age (year) & $31.6 \pm 8.8$ & $23.8 \pm 2.8$ & & $19.7 \pm 0.9$ & & $24.0 \pm 4.7$ & $26.7 \pm 6.5$ \\
\hline Heigh $(\mathrm{cm})$ & $167.4 \pm 9.3$ & $180 \pm 7.0$ & $177.5 \pm 8.6$ & $173.0 \pm 4.5$ & $175.2 \pm 7.5$ & $169.6 \pm 4.8$ & $179 \pm 4.7$ \\
\hline Weight $(\mathrm{kg})$ & $65.4 \pm 12.0$ & $72.4 \pm 8.7$ & $69.5 \pm 6.2$ & $66.9 \pm 7.0$ & $71.9 \pm 12.2$ & $64.2 \pm 7.0$ & $86.1 \pm 8.2$ \\
\hline$\%$ Fat Mass & $14.7 \pm 4.3$ & $8.1 \pm 2.4$ & $11.0 \pm 3.2$ & $14.2 \pm 5.3$ & $12.9 \pm 5.1$ & - & $16.8 \pm 2.5$ \\
\hline Endomorphic & 4.0 & 2.1 & 2.3 & 3.2 & 2.7 & 2.4 & 3.7 \\
\hline Mesomorphic & 4.2 & 3.5 & 4.5 & 4.3 & 4.0 & 4.7 & 5.8 \\
\hline Ectomorphic & 2.1 & 3.1 & 3.0 & 2.7 & 2.3 & 2.5 & 1.3 \\
\hline
\end{tabular}

Table for comparison purposes, showing mean \pm SD data reported by authors. (-) represents no available information. 
The reduced sample size included in our research could represent a possible source of bias and suggest some prudence when interpreting research findings. Further studies should be performed including athletes from lower categories that could benefit from the information obtained to potentiate their training.

SÁNCHEZ-PUCCINI, M. B.; ARGOTHY-BUCHELI, R. E.; MENESES-ECHÁVEZ, J. F.; LÓPEZ-ALBÁN, C. A. \& RAMÍREZ-VÉLEZ, R. Caracterización antropométrica y estado físico de atletas de elite de karate masculino. Int. J. Morphol., 32(3):1026-1031, 2014.

RESUMEN: El objetivo del estudio fue evaluar las características antropométricas y del estado físico de los atletas de elite karate maculino. Nuestro estudio se realizó sobre una muestra de 19 atletas karatecas de Colombia (edad media de 31,6 $\pm 8,8$ años). Se tomaron diferentes medidas antropométricas (peso, talla, diámetros, circunferencias, composición corporal) a partir de las cuales se calcularon varios índices antropométricos (índice de masa corporal, índice ponderal, índice de adiposidad corporal), permitiendo determinar el somatotipo. Las pruebas de rendimiento realizadas fueron: el protocolo Astrand-Ryming, salto vertical, potencia anaeróbica y la prueba anaeróbica de Wingate. Se obtuvieron los resultados (Media \pm DE) de masa corporal $(65,4 \pm 12,0 \mathrm{~kg}$ ), altura $(167,4 \pm 9,3 \mathrm{~cm})$, porcentaje de grasa corporal $(13,6 \pm 3,0 \%)$, índice ponderal $(41,0 \pm 1,8)$ e índice de adiposidad corporal $(25,1 \pm 3,6)$. Los valores de los componentes del somatotipo, de acuerdo con el método de Heath-Carter, fueron de 4,0-4,2-2,1 para los componentes endomórfico, mesomórfico, y ectomórfico, respectivamente. El promedio para la capacidad aeróbica fue $(44,8 \pm 7,1$ $\left.\mathrm{ml} \bullet \mathrm{kg}^{1} \bullet \mathrm{min}^{-1}\right)$, del salto vertical $(32,0 \pm 8,7 \mathrm{~cm})$, de potencia anaeróbica $\left(90,1 \pm 22,7 \mathrm{~kg} \bullet \mathrm{s}^{-1}\right)$ y de capacidad anaeróbica $(5.748,7 \pm 1.477,5 \mathrm{~W})$. Estos resultados permiten obtener un perfil del karateca de elite, que puede ser utilizado como blanco de formación para el desarrollo de estos atletas. Los resultados también pueden proporcionar información que busque enfatizar el entrenamiento y desarrollo de tácticas.

KEY WORDS: Karate; Composición corporal; Somatotipo; Fitness; Antropometría.

\section{REFERENCES}

Bar-Or, O. The Wingate anaerobic test. An update on methodology, reliability and validity. Sports Med., 4(6):381-94, 1987.

Bergman, R. N.; Stefanovski, D.; Buchanan, T. A.; Sumner A. E.; Reynolds, J. C.; Sebring, N. G.; Xiang, A. H.; \&Watanabe, R. M. A better index of body adiposity. Obesity (Silver Spring), 19(5):1083-9, 2011

Carter, J. E. L. \& Heath, B. H. Somatotyping: development and application. New York, Cambridge University Press, 1990.
García, J.; Cañadas, M. \& Parejo, I. Una revisión sobre la detección y selección del talento en balonmano. e-balonmano.com; 3(3):39-46, 2007.

Giampietro, M.; Pujia, A. \& Bertini, I. Anthropometric features and body composition of young athletes practicing karate at a high and medium competitive level. Acta Diabetol., 40(Suppl. 1):S145-8, 2003.

Huertas, G.; De-los-Santos, H.; Bersain, D. \& Cabrera, C. Estudio antropométrico de la elite sudamericana juvenil de karate. ISEF Digital, 8:1-37, 2006.

Marfell-Jones, M.; Olds, T.; Stewart, A. D. \& Carter, L. International Standards for Anthropometric Assessment. Potchefstroom, South Africa, International Society for the Advancement of Kinanthropometry (ISAK), 2006.

Moreno, G. A.; Moreno, L. E. A. \& Jaramillo, P. C. A. Characterization of karate athletes and college basketball: body composition and anthropometry saltability. Rev. Edu-Fisica, 3(8):1-20, 2011

Nevill, A. M.; Metsios, G. S.; Jackson, A. S.; Wang, J.; Thornton, J. \& Gallagher, D. Can we use the Jackson and Pollock equations to predict body density/fat of obese individuals in the 21st century? Int. J. Body Compos. Res., 6(3):114-21, 2008.

Pieter, W. \& Bercades, L. T. Somatotype of national elite combative sport athletes. Braz. J. Biomot., 3(1):21-30, 2009.

Popovic, S.; Akpinar, S.; Jaksic, D.; Matic, R. \& Bjelica, D. Comparative Study of Anthropometric Measurement and Body Composition between Elite Soccer and Basketball Players. Int. J. Morphol., 31(2):461-7, 2013.

Sterkowicz-Przybycien, K. L. Body composition and somatotype of the top of Polish male karate contestants. Biol. Sport, 27(3):195-201, 2010.

Vodak, P. Assessing the athletic potential of young athletes. In: Smith, N. J. (Ed.). Sports Medicine: Health Care for Young Athletes. Evanston, American Academy of Pediatrics, 1983. pp.32-58.

Correspondence to:

Robinson Ramírez-Vélez

Universidad Santo Tomás

Carrera $9 \mathrm{~N}^{\circ}$ 51-23

Bogotá, D.C.

COLOMBIA

Email: robin640@hotmail.com
Recibido : 27-06-2014

Aceptado: 27-07-2014 